JUST TI: (Jurnal Sains Terapan Teknologi Informasi) 13, 1 (Januari, 2021): 22-28

Website: e-journal.polnes.ac.id/index.php/justi

ISSN: 2579-4510(online) ISSN: 2085-6458(print)

\title{
Sistem Monitoring Gas Chloro Fluro Carbon (CFC) Pada Air Conditioner (AC) Dengan Menggunakan Arduino Dan Sensor MPX5700AP
}

\author{
Hernawan Rofi Kurnianto ${ }^{1)}$, Wahyu Sapto Aji ${ }^{2)}$ \\ ${ }^{1)}$ Universitas Ahmad Dahlan, Yogyakarta, Indonesia \\ Kampus 4 Universitas Ahmad Dahlan, Jln. Ring Road Selatan, Tamanan, Banguntapan, \\ D.I.Yogyakarta, Indonesia \\ ${ }^{11}$ hrofi96@gmail.com, ${ }^{2)}$ wahyusa@ee.uad.ac.id
}

\begin{abstract}
Abstrak - Permasalahan yang muncul pada sistem Air Conditioner (AC) adalah pengguna tidak mengetahui kondisi gas Chloro Fluro Carbon (CFC). Oleh karena itu penelitian ini mengusulkan tentang sistem monitoring gas CFC pada sistem Air Conditioner. Sistem monitoring sangat penting karena membantu mengetahui kinerja alat. Sistem monitoring ini menggunakan sensor MPX5700AP untuk membaca tekanan gas CFC dan Arduino sebagai sistem pengolahan data. Sistem monitoring juga dilengkapi dengan sistem alarm untuk memberi peringatan ke pengguna. Hasil olah data Arduino akan dimunculkan menjadi notifikasi pada LCD 16x2 sehingga pengguna dapat mengetahui kondisi gas CFC. Pengukuran tekanan gas CFC menggunakan perbandingan pengukuran antara sensor MPX5700AP dengan standar alat ukur gauge manifold. Berdasarkan pengujian sistem yang diusulkan mampu bekerja dengan baik. Sensor dapat mengukur perubahan tekanan, Arduino dapat mengolah data dan sistem ini mampu memunculkan angka pada layar LCD 16x2 sebagai notifikasi dan alarm akan berbunyi pada tekanan 49,95Psi. Prototipe hardware ini memiliki keakuratan pengukuran sebesar 99,12\% dibandingkan dengan alat kalibrasi. Berdasarkan pengujian sistem dapat diterapkan untuk membantu pengguna memantau kondisi gas CFC pada AC.
\end{abstract}

Kata-kata Kunci - Sistem Monitoring, Arduino, Air Conditioner, MPX5700AP, Sensor Tekanan

\section{PENDAHULUAN}

Perangkat AC (Air Conditioner) adalah suatu alat yang digunakan untuk mengatur udara pada kondisi tertentu untuk mencapai kenyamanan termal pengguna [1]. Perangkat AC memerlukan suatu sistem yang dapat mengetahui dan melihat kondisi keadaan pada AC tersebut, seperti mengetahui dan melihat kondisi gas Chloro Fluro Carbon (CFC). Pada perangkat AC, gas CFC adalah bahan utama yang membuat perangkat $\mathrm{AC}$ dapat menciptakan udara dingin. Gas CFC ini adalah gabungan senyawa Klorin, Fluorin, dan Karbon [2][3]. Berdasarkan hal tersebut pematauan atau monitoring gas CFC diperlukan agar kondisi gas CFC dapat diketahui dan perangkat $\mathrm{AC}$ dapat menghasilkan kinerja yang sesuai, yaitu menghasilkan udara yang selalu dingin. Sistem ini juga akan dilengkapi dengan suatu tanda berupa alarm dan notifikasi apabila gas CFC bertekanan rendah. Oleh karena itu pengguna dapat mengetahui jika kondisi gas CFC sudah habis.

Sistem monitoring sangat penting karena dapat membantu mengetahui kinerja suatu alat [4]. Penelitian sejenis pernah dilakukan oleh peneliti sebelumnya untuk memonitor kondisi Cairan Infus [5], suhu tubuh [6], Gas Medis [7], Tegangan Baterai [8][9], dan Bahan bakar [10]. Berdasarkan hal tersebut belum ada penelitian terkait monitoring gas CFC pada sistem AC, oleh karena itu penelitian ini mengusulkan tentang sistem monitoring tekanan gas CFC pada sistem AC.

Selain sistem monitoring sistem yang diusulkan juga dilengkapi dengan sistem alarm. Sistem monitoring gas CFC pada AC menggunakan sensor dengan tipe sensor Tekanan. Sensor tekanan adalah tipe sensor yang dapat membaca nilai tekanan udara besar [11]. Sensor yang digunakan pada sistem ini adalah sensor MPX5700AP. Pembacaan nilai tekanan sensor MPX5700AP kemudian diolah menggunakan Arduino. Arduino adalah board open source khusus yang mempunyai input output khusus [12][13][14]. Kemudian sistem dilengkapi dengan alarm menggunakan buzzer aktif, lalu untuk menampilkan data monitoring dari kondisi tekanan gas CFC pada AC yang terbaca oleh sensor MPX5700AP menggunakan LCD 16x2. 


\section{METODE}

Sistem alarm monitoring gas CFC pada Air Conditioner (AC) bertujuan untuk mengetahui kondisi dari tekanan gas CFC yang terdapat pada AC dan ditampilkan pada LCD 16x2 dan buzzer. Data yang ditampilkan pada LCD 16x2 adalah data tekanan yang terbaca oleh sensor MPX5700AP. Data tekanan tersebut kemudian akan diolah menggunakan Arduino untuk menyalakan sistem alaram. Sistem alaram yang digunakan menggunakan buzzer. Buzzer akan aktif saat sensor membaca tekanan $<=50 \mathrm{psi}$, dan buzzer akan mati saat sensor membaca tekanan >50psi. Pengambilan data dilakukan dengan perbandingan 2 pengukuran menggunakan sensor MPX5700AP dan menggunakan gauge manifold, kemudian dianalisis menggunakan metode perhitungan standar deviasi [15][16]. Standar deviasi digunakan untuk melihat nilai keakuratan dari perbandingan alat ukur gauge manfold dan sensor MPX5700AP. Tekanan yang di baca oleh sensor adalah tekanan tipe absolute pressure. Tekanan absolute pressure adalah tekanan yang mengukur perbandingan antara tekanan yang terukur dengan tekanan udara di sekitarnya [17].

\section{METODE}

\subsection{Desain Sistem}

Diagram blok sistem ditunjukkan pada Gambar 1. Perancangan sistem pada penelitian yang dibuat ini menggunakan bahan utama gas CFC (Chloro Fluro Carbon) pada Air Condtioner. Tekanan pada gas tersebut dibaca menggunakan sensor MPX5700AP. Hasil yang terbaca sensor MPX5700AP akan diolah menggunakan Arduino. Pengolahan data tekanan pada Arduino akan mempunyai hasil yang dikeluarkan dalam bentuk nilai data pada LCD16x2 dan membunyikan buzzer jika tekanan melewati batas tertentu.

Rancang bangun alarm monitoring gas CFC menggunakan Arduino dan sensor MPX5700AP menggunakan alat dan bahan penunjang lain yang dapat membantu agar hasil prototipe hardware baik. Alat dan bahan yang digunakan seperti pada Tabel 1.

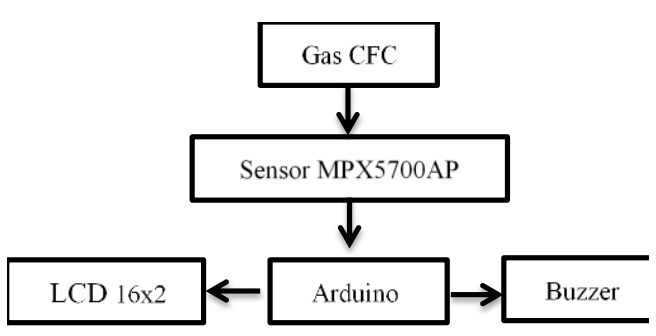

Gambar 1 Diagram Blok Sistem

Tabel 1. Alat dan Bahan Penelitian

\begin{tabular}{c|c|c}
\hline No & Alat dan Bahan & Jumlah \\
\hline 1 & Tabung gas CFC & 1 \\
\hline 2 & Air Conditoner & 1 \\
\hline 3 & Tabung kompresor & 1 \\
\hline 4 & Kompresor angin & 1 \\
\hline 5 & Selang Cuck Valve & 1 \\
\hline 8 & IC Atmega 328 & 1 \\
\hline 9 & Sensor MPX5700AP & 1 \\
\hline 10 & Buzzer & 1 \\
\hline 11 & LCD 16x2 & 1 \\
\hline 12 & Sumber Power 12VDC & 1 \\
\hline
\end{tabular}

\subsection{Diagram Pengkabelan}

Sistem alaram monitoring gas CFC menggunakan Arduino, sensor MPX5700AP, buzzer, LCD 16x2 yang dirangkai menjadi suatu sistem yang saling terhubung menggunakan wiring kabel. Wiring dari sistem tersebut seperti pada Gambar 3. Data sensor tersebut dibaca dengan menggunakan fasilitas analog to digital converter (ADC )yaitu fitur untuk mengonversi data analog menjadi data digital [9].

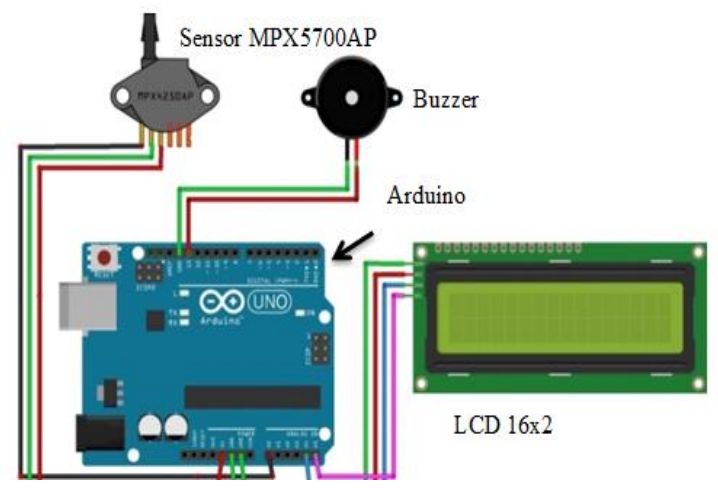

Gambar 1 Diagram Pengkabelan Sistem

\subsection{Algoritma}

Arduino digunakan pada sistem ini untuk mengolah data yang terbaca oleh sensor MPX5700AP untuk menjadi pemicu buzzer alarm 
JUST TI: (Jurnal Sains Terapan Teknologi Informasi) 13, Januari, 2021: 22-28 ISSN: 2579-4510(online) ISSN: 2085-6458(print)

agar menjadi aktif. Buzzer aktif apabila tekanan gas CFC pada $<=50$ psi, dan buzzer mati apabila tekanan gas $\mathrm{CFC}>50$ psi. Arduino juga mengolah data tekanan untuk dikeluarkan pada layar LCD16x2. Alur olah data Arduino dapat dibuat flowchart seperti pada Gambar 2.

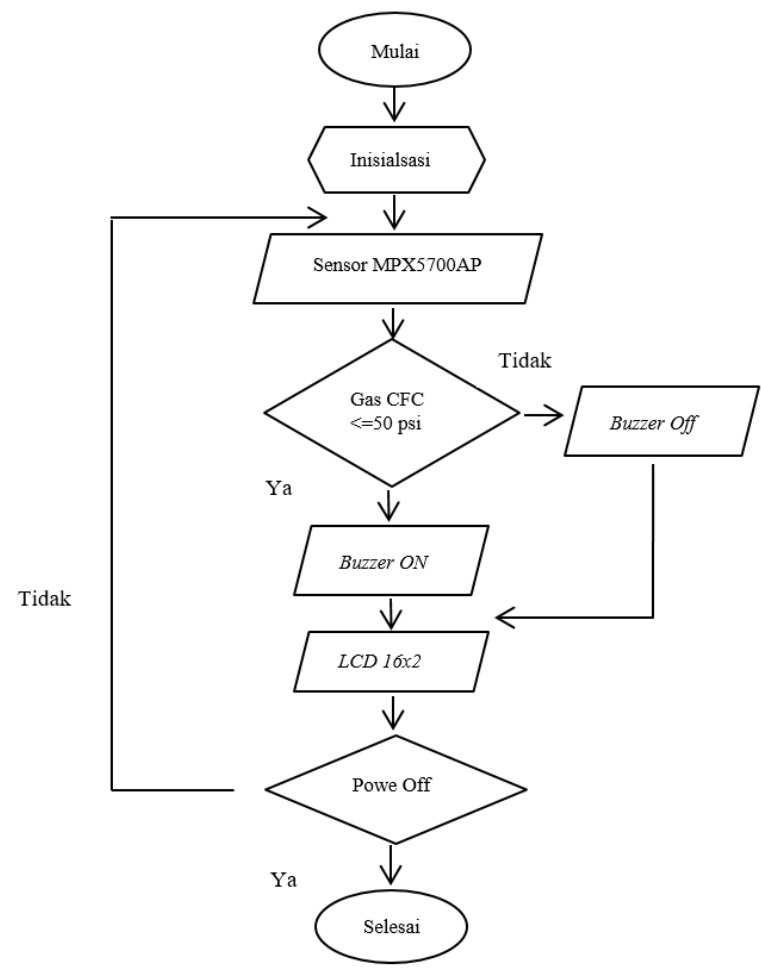

Gambar 2. Diagram Alir Sistem

\subsection{Metode Analisa}

Analisis data yang digunakan pada penelitian ini menggunakan standar deviasi yang digunakan untuk mengetahui nilai keakuratan dari data yang diambil melalui pengukuran tekanan gas CFC secara langsung menggunakan sensor MPX5700AP dan dibandingkan dengan alat gauge manifold. Jika hasil nilai standar deviasi memiliki nilai sama dengan 0 (nol) atau mendekati 0 (nol) maka alat tersebut dapat dikatakan baik [8][9]. Sebelum menghitung standar deviasi, data-data tersebut harus dihitung nilai rata-rata terlebih dahulu yaitu menggunakan persamaan (1), berikut ini,

$$
\bar{x}=\frac{1}{n} \sum_{n-1}^{n} x_{i}
$$

Selanjutnya menghitung nilai standar deviasi adalah

$$
\sigma=\sqrt{\frac{n \sum_{i=1}^{n}\left(x_{i}-\bar{x}\right)^{2}}{(n-1)}}
$$

Dengan variabel $\sigma$ adalah Standar deviasi, $n$ adalah Jumlah sampel, $\bar{x}$ adalah rata - rata dan $x_{i}$ adalah nilai $\mathrm{x}$ ke- $i$.

\section{HASIL DAN PEMBAHASAN}

\subsection{Hasil Prototipe Alat}

Hasil penelitian alarm monitoring gas CFC menggunakan Arduino dan sensor MPX5700AP adalah prototipe Hardware berbentuk Box akrilik dengan ukuran lebar $15 \mathrm{~cm}$ dan panjang $20 \mathrm{~cm}$ terbuat dari bahan akrilik. Pada bagian depan alat terdapat layar LCD16x2 dan buzzer. Pada bagian dalam terdapat Arduino dan sumber Power. Pada bagian samping terdapat sensor dan katup keran untuk membuka dan menutup aliran gas. Bentuk prototipe Hardware seperti Gambar 4 dan Gambar 5.

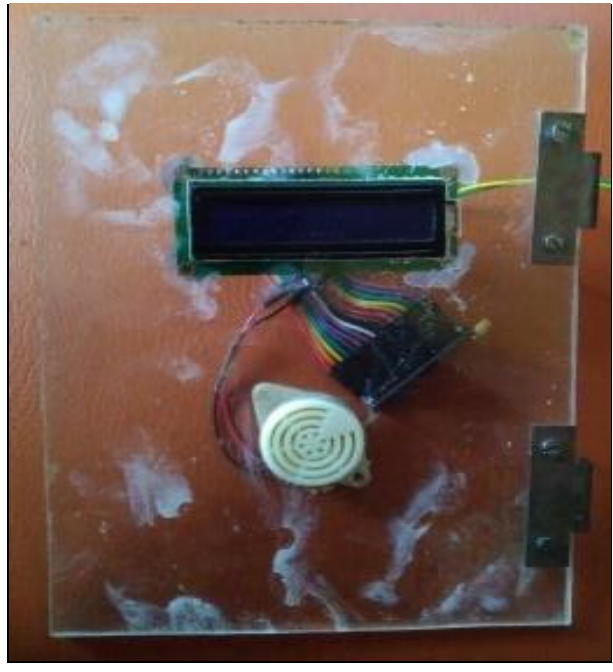

Gambar 4. Prototipe Tampak Bagian Depan 


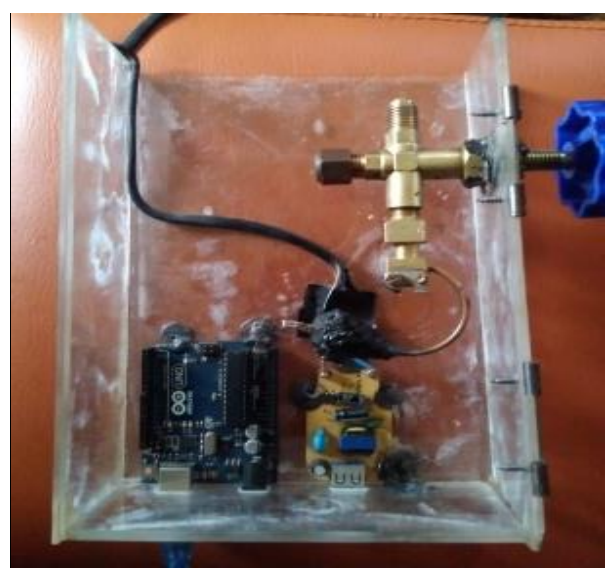

Gambar 5. Prototipe Tampak Bagian Belakang

Prototipe hardware pada gambar 4, dan gambar 5 terbuat dari bahan akrilik karena akrilik tidak tembus air dan terbuat dari bahan yang tidak mengalirkan listrik (isolator). Pada pemasangan sebenarnya prototipe hardware gambar 4 dan gambar 5 akan di pasang di luar ruangan di samping AC luar, dan keran prototipe hardware akan disambungkan pada pipa hisap yang terletak pada kompresor AC.

\subsection{Uji LCD}

Pengujian LCD dilakukan untuk melihat nilai yang dikeluarkan pada layar LCD 16x2 sesuai dengan pembacaan dari sensor MPX5700AP seperti ditunjukkan pada Gambar 5.

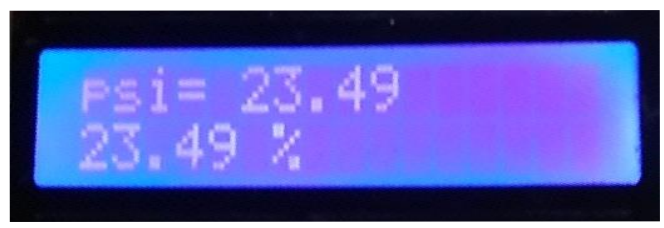

Gambar 5 Hasil Pengujian LCD

Nilai yang muncul pada layar LCD 16x2 tersebut adalah nilai tekanan yang terbaca oleh sensor MPX5700AP dan hasil persentase dari tekanan tersebut. Hasilnya seperti pada Tabel 2.

Tabel 2. Hasil Pengujian LCD

\begin{tabular}{cccc}
\hline \multirow{2}{*}{ No } & \multirow{2}{*}{ Tekanan } & \multicolumn{2}{c}{ Layar LCD } \\
\cline { 3 - 4 } & & Tekanan & $\begin{array}{c}\text { Persentase } \\
\text { \% }\end{array}$ \\
\hline 1 & 15 Psi & 23,49 Psi & $23,49 \%$ \\
\hline 2 & 16 Psi & 24,44 Psi & $24,44 \%$ \\
\hline 3 & 17 Psi & 25,33 Psi & $25,33 \%$ \\
\hline
\end{tabular}

\begin{tabular}{c|c|c|c}
4 & 18 Psi & 26,44 Psi & $26,44 \%$ \\
\hline 5 & 19 Psi & 27,33 Psi & $27,33 \%$ \\
\hline 6 & 20 Psi & 28,78 Psi & $28,78 \%$ \\
\hline 7 & 21 Psi & 29,11 Psi & $29,11 \%$ \\
\hline 8 & 22 Psi & 30,4 Psi & $30,44 \%$ \\
\hline 9 & 23 Psi & 31,33 Psi & $31,33 \%$ \\
\hline 10 & 24 Psi & 32,44 Psi & $32,44 \%$ \\
\hline
\end{tabular}

Dapat diketahui dari Tabel 3. Bahwa LCD 16x2 dapat bekerja dengan baik sesuai pada program Arduino yaitu memunculkan nilai tekanan yang terbaca sensor MPX5700AP dan nilai persentase dari tekanan tersebut.

\subsection{Uji Sensor}

Uji sensor ini bertujuan untuk mengetahui apakah sensor MPX5700AP yang dipakai pada sistem dapat digunakan dengan baik sesuai dengan rentan kerja yang dapat dilakukan oleh sensor MPX5700AP. Uji sensor ini akan membandingkan pengukuran rentan kerja sensor pada nilai yang terdapat di datasheet dengan nilai yang didapat pada pengujian sensor MPX5700AP secara langsung. Setelah mendapatkan nilai-nilai pengukuran tersebut dapat menghitung nilai error rata-rata dan nilai standar deviasi. Hasil nilai-nilai yang didapatkan pada uji sensor seperti Tabel 3 .

\begin{tabular}{|c|c|c|c|c|}
\hline \multirow[t]{2}{*}{$\begin{array}{l}\mathbf{N} \\
\mathbf{0}\end{array}$} & \multirow{2}{*}{$\begin{array}{c}\text { Tekana } \\
\text { n } \\
(\text { psi) }\end{array}$} & \multicolumn{3}{|c|}{$\begin{array}{c}\text { Penguku } \\
\text { r-an } \\
\text { Langsun } \\
\text { g } \\
\end{array}$} \\
\hline & & $\begin{array}{c}\text { Teganga } \\
\text { n A } \\
(\mathbf{v})\end{array}$ & $\begin{array}{c}\text { Teganga } \\
\text { n B } \\
\text { (v) }\end{array}$ & $\begin{array}{c}\text { Error } \\
\text { Tegangan }\end{array}$ \\
\hline 1 & 0 & 0 & 0 & 0 \\
\hline 2 & 15 & 1 & 1 & 0 \\
\hline 3 & 20 & 1 & 1,5 & 0,5 \\
\hline 4 & 30 & 1,5 & 2 & 0,5 \\
\hline 5 & 40 & 2,1 & 2,5 & 0,4 \\
\hline 6 & 50 & 3 & 3 & 0 \\
\hline 7 & 60 & 3 & 3,5 & 0,5 \\
\hline 8 & 70 & 3 & 3,5 & 0,5 \\
\hline 9 & 80 & 4 & 4,5 & 0,5 \\
\hline 10 & 100 & 4,5 & 5 & 0,5 \\
\hline
\end{tabular}


JUST TI: (Jurnal Sains Terapan Teknologi Informasi) 13, Januari, 2021: 22-28

ISSN: 2579-4510(online) ISSN: 2085-6458(print)

Nilai rata-rata error adalah

$$
\overline{\mathrm{x}}=\frac{34}{10}=0,34
$$

Hasil dari perhitungan nilai rata-rata error menunjukkan nilai 0,34 yang berarti pengukuran keseluruhan tegangan yang dilakukan pada sensor MPX5700AP akan mendapatkan nilai 0,34 lebih besar dari nilai tegangan pada datasheet.

Nilai standar deviasi adalah

$$
\sigma=\sqrt{\frac{18,5}{9}}=0,2
$$

Hasil dari perhitungan standar deviasi menunjukkan nilai 0,23 yang berarti bahwa pengukuran tegangan pada sensor MPX5700AP mempunyai akurasi sebesar $99,27 \%$, yang didapatkan dari nilai akurasi ideal $100 \%-0,23=$ 99,27.

\subsection{Pengujian Buzzer}

Pengujian buzzer bertujuan untuk mengetahui apakah buzzer dapat bekerja sesuai dengan yang program pada Arduino yaitu buzzer akan aktif pada saat tekanan gas $\mathrm{CFC}<=50$ psi dan akan mati pada saat tekanan gas CFC nilai $>50$ psi. Dan hasil dari pengujian buzzer seperti pada Tabel 4.

Tabel 4. Alat dan Bahan Penelitian

\begin{tabular}{c|c|c}
\hline \multirow{2}{*}{ No } & \multicolumn{2}{c}{ Nilai Tekanan (Psi) } \\
\cline { 2 - 3 } & Alarm On & Alarm Off \\
\hline 1 & 49,95 & 50,06 \\
\hline 2 & 49,84 & 50,17 \\
\hline 3 & 49,73 & 50,28 \\
\hline 4 & 49,62 & 50,39 \\
\hline 5 & 49,51 & 50,5 \\
\hline 6 & 49,4 & 50,61 \\
\hline 7 & 49,29 & 50,72 \\
\hline 8 & 49,18 & 50,83 \\
\hline 9 & 49,07 & 50,94 \\
\hline 10 & 48,96 & 51,05 \\
\hline
\end{tabular}

Dapat diketahui dari Tabel 4. Bahwa buzzer dapat bekerja dengan baik sesuai pada program Arduino yaitu buzzer aktif pada saat tekanan yang gas CFC 49,95 psi $(<50$ psi) dan akan mati pada saat tekanan gas CFC adalah 50,06 psi (>50 psi).

\subsection{Pengujian Tekanan}

Proses pengambilan data yang dilakukan dengan mengambil nilai tekanan gas CFC pada tabung kompresor AC dengan menggunakan sensor MPX5700AP dan dibandingkan dengan pengukuran menggunakan acuan standar dar alat ukur gauge manifold sebanyak 10 data, dari hasil tersebut dianalisis dengan metode standar deviasi. Hasil pengambilan data seperti pada Tabel 5 dan Tabel 6.

Tabel 5. Pengujian Tekanan 40-50

\begin{tabular}{c|c|c|c|c|c|c}
\hline \multirow{2}{*}{ No } & \multicolumn{6}{c}{ Hasil Pembacaan Sensor } \\
\cline { 2 - 7 } & $\mathbf{5 0}$ Psi & Error & 45 Psi & Error & 40 Psi & error \\
\hline 1 & 57,44 & 7,44 & 52,81 & 7,81 & 48,4 & 8,4 \\
\hline 2 & 57,44 & 7,44 & 52,81 & 7,81 & 48,4 & 8,4 \\
\hline 3 & 57,33 & 7,33 & 52,7 & 7,7 & 48,29 & 8,29 \\
\hline 4 & 57,33 & 7,33 & 52,7 & 7,7 & 48,29 & 8,29 \\
\hline 5 & 57,22 & 7,22 & 52,59 & 7,59 & 48,18 & 8,18 \\
\hline 6 & 57,22 & 7,22 & 52,59 & 7,59 & 48,18 & 8,18 \\
\hline 7 & 57,11 & 7,11 & 52,48 & 7,48 & 48,07 & 8,07 \\
\hline 8 & 57,11 & 7,11 & 52,48 & 7,48 & 48,07 & 8,07 \\
\hline 9 & 57 & 7 & 52,37 & 7,37 & 47,96 & 7,96 \\
\hline 10 & 57 & 7 & 52,37 & 7,37 & 47,96 & 7,96 \\
\hline
\end{tabular}

\begin{tabular}{|c|c|c|c|c|c|c|}
\hline \multirow{2}{*}{ No } & \multicolumn{6}{|c|}{ Hasil Pembacaan Sensor } \\
\hline & 35 Psi & error & $30 \mathrm{Psi}$ & Error & 25 Psi & error \\
\hline 1 & 44,21 & 1,88 & 39,25 & 9,25 & 33,52 & 8,52 \\
\hline 2 & 44,21 & 1,88 & 39,25 & 9,25 & 33,53 & 8,53 \\
\hline 3 & 44,1 & 1,59 & 39,14 & 9,14 & 33,41 & 8,41 \\
\hline 4 & 44,1 & 1,59 & 39,14 & 9,14 & 33,41 & 8,41 \\
\hline 5 & 43,99 & 1,32 & 39,03 & 9,03 & 33,3 & 8,3 \\
\hline 6 & 43,99 & 9,21 & 39,03 & 9,03 & 33,3 & 8,3 \\
\hline 7 & 43,88 & 9,21 & 38,92 & 8,92 & 33,19 & 8,19 \\
\hline 8 & 43,88 & 9,1 & 38,92 & 8,92 & 33,19 & 8,19 \\
\hline 9 & 43,77 & 9,1 & 38,81 & 8,81 & 33,08 & 8,08 \\
\hline 10 & 43,77 & 8,99 & 38,81 & 8,81 & 33,08 & 8,08 \\
\hline
\end{tabular}

Tabel 6. Pengujian Tekanan 25-35 
Nilai rata-rata error adalah

$$
\overline{\mathrm{x}}=\frac{587,51}{70}=8,3
$$

Hasil dari perhitungan nilai rata-rata error menunjukkan nilai 8,3 yang berarti bahwa pengukuran keseluruhan tekanan yang dilakukan pada sensor MPX5700AP akan mendapatkan nilai 8,3 lebih besar dari nilai tekanan yang terukur pada gauge manifold.

Nilai standar deviasi adalah

$$
\sigma=\sqrt{\frac{52,98}{69}}=0,9
$$

Hasil dari perhitungan standar deviasi menunjukkan nilai 0,9 yang berarti bahwa pengukuran tegangan pada sensor MPX5700AP mempunyai akurasi sebesar 99,1\% , yang didapatkan dari nilai akurasi ideal 100\% - 0,9= 99,1 .

\section{KESIMPULAN}

Dari penelitian alarm monitoring gas $\mathrm{CFC}$ dengan menggunakan Arduino dan sensor MPX5700AP mendapatkan kesimpulan bahwa sistem alarm dapat berbunyi pada saat tekanan gas CFC berada pada tekanan 49,95psi dan akan mematikan sistem alarm pada tekanan 50,05psi. Sistem yang dibuat dapat menghasilkan standar deviasi 0,9, keakuratan pengukuran 99,1\%.

Prototipe Hardware ini masih dapat dikembangkan lagi menjadi lebih baik, dan penulis sangat merekomendasikan memilih sensor yang mempunyai rentan ukur pembacaan tekanan yang lebih besar. Monitoring pada sistem dapat dikembangkan menggunakan proses IoT (Internet of Things).

\section{REFERENSI}

[1] A. A. Ilham, Syafaruddin, and A. A. S. Ramschie, "Sistem Monitoring dan Kendali Kerja Air Conditioning Berbasis Mikrokontroller ATmega 8535," Jurnal Ristek, vol. 2, no. 1, pp. 33-37, 2013.

[2] K. R. Edi Purwanto, "Pengaruh Jenis Refrigerant Dan Beban Pendinginan Terhadap Kemampuan Kerja Mesin Pendingin," Turbo : Jurnal Program Studi Teknik Mesin, vol. 3, no. 1, pp. 11-16, 2014.

[3] B. C. Purnomo and M. Setiyo, "Karakteristik Sistem Refrigerasi Kompresi Uap Dengan Refrigerant Campuran Musicool 134 - Co2,"
Jurnal Teknologi, vol. 9, no. 2, p. 57, 2017.

[4] V. Y. Muhammad, A. Ma'arif, and S. Sunardi, "Purwarupa Alat Ukur Kandungan pH, Suhu Air dan Suhu Udara pada Pertanian Hidroponik," Jurnal Ilmiah Teknologi Pertanian Agrotechno, vol. 5, no. 2, p. 81, Oct. 2020.

[5] Iswanto, M. S. Masnawan, N. M. Raharja, and A. Ma'arif, "Infusion Liquid Level Detection Tool Using IR Sensors and Photodiode Based on Microcontroller," in Proceeding - 2020 2nd International Conference on Industrial Electrical and Electronics, ICIEE 2020, 2020, pp. 70-73.

[6] A. N. N. Chamim, J. Rinaldi, Y. Ardiyanto, I. Iswanto, and A. Ma'Arif, "Heart Rate and Body Temperature Monitoring Based on Android Operating System," in Proceeding - 2020 2nd International Conference on Industrial Electrical and Electronics, ICIEE 2020, 2020, pp. 143-148.

[7] N. H. Wijaya, B. Untara, and I. Khoirunnisa, "Monitoring Tekanan Gas Medis Pada Instalasi Gas Medis Rumah Sakit," Medika Teknika : Jurnal Teknik Elektromedik Indonesia, vol. 1, no. 1, pp. 19-24, Oct. 2019.

[8] M. Setiawan and R. D. Puriyanto, "Arduino-Based Battery Voltage Monitoring and SMS Gateway," Buletin Ilmiah Sarjana Teknik Elektro, vol. 2, no. 3, pp. 111-118, 2020.

[9] R. I. Putra, S. Sunardi, and R. D. Puriyanto, "Monitoring Tegangan Baterai Lithium Polymer pada Robot Line Follower Secara Nirkabel," Buletin Ilmiah Sarjana Teknik Elektro, vol. 1, no. 2, pp. 73-81, 2019.

[10] Y. I. Pranata and Muchlas, "Simulation of Telemetry System for Monitoring Fuel Level Based on SMS Gateway," Buletin Ilmiah Sarjana Teknik Elektro, vol. 2, no. 1, pp. 33-39, 2020.

[11] A. H. Noviyanto, "Aplikasi Sensor Tekanan Mpxm2053Gs Pada Alat Uji Tekanan Sphygmomanometer Berbasis Mikrokontroler Atmega328," vol. 21, no. 1, pp. 87-94, 2017.

[12] A. B. S. Sugeng Harianto, "Studi Tentang Penggunaan Metode Scanning Pada Sistem Telemetri Pendeteksi Kerusakan Air Conditioner Kendaraan," Elektrika, vol. 01, no. September, pp. 47-51, 2017.

[13] A. Amin, "Monitoring Water Level Control Berbasis Arduino Uno Menggunakan Lcd Lm016L," Jurnal Ilmiah Teknik Elektro, vol. 1, no. 2, pp. 41-52, 2018.

[14] Bahrin, "Sistem Kontrol Penerangan Menggunakan Arduino Uno Pada Universitas Ichsan Gorontalo," ILKOM Jurnal Ilmiah, vol. 9, no. 3, pp. 282-289, 2017.

[15] N. Nafi'yah, "Perbandingan Modus, Median, K Standar Deviasi, Iterative, Mean Dan Otsu Dalam Thresholding," vol. 8, no. 2, pp. 31-36, 2016.

[16] R. S. Pertumpuan Gurusingan, "Analisa Rata-rata Nilai Fisika Dengan Metode Ekspositori dan Inkuri Difakultas Teknik Universitas Satya Negara Indonesia.". 
JUST TI: (Jurnal Sains Terapan Teknologi Informasi) 13, Januari, 2021: 22-28

ISSN: 2579-4510(online) ISSN: 2085-6458(print)

[17] S. Riswanto, "Pengukuran Tekanan Absolute Biogas Berbahan Campuran Eceng Gondok dan Kotoran Sapi," Journal of Chemical Information and Modeling, vol. 53, no. 9, pp. 1689-1699, 2019. 